CCRL-52990

Distribution Category CC-11

\title{
The national uranium resource evaluation program: the hydrogeochemical stream sediment reconnaissance program at LLNL
}

\author{
Gary H. Higgins
}

Manuscript date: Ȧugust 1980

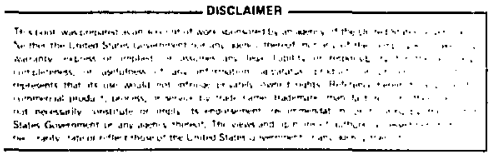

LAWRENCE LIVERMORE LABORATORY

University of California $\bullet$ Livermore, California $\bullet 94550$ 
This report documents the work of Lawrence Livermore National Laboratory on the Hydrogeochemical stream Sediment Reconnaissanse (HSSR) which is part of the National Uranium Resource Evaluation (NURE) program sponsored by the Department of Energy (DOE). The laboratory participated in this Erogram from early 1975 to mid 1979. Originally, the laboratory assumed responsibility for collecting, analyzing, and evaluating sediment and water samples from nearly 200,000 sites in the western United States to locate areas favo. ?ble for uranium exploration; however, ILNL's participation in the progral. was terminated in June 1979 after the NURE program staff redefined the objec $\vdots$ ve to that of refining uranium reserve estimates. LLNL's objectives and methodologi.es were considered inconsistent with those of the RURE program office, and the LINL geochemical studies could not be used to improve reserve est ima tes.

The author wishes to thank the members of the NURE team for thei: heroic efforts to maintain the program schedule in spite of nearly overwhelm.i-lg odds. Special thanks are due to Ms. Barbara Gumm, Dr. William Hutckin, Mr. Arthur Langhorst, Dr. Charles Smith, and Dr. Richard Van Konynenrurg for their review of, and correction to, the original manuscript. 
iv 
CONTENTS

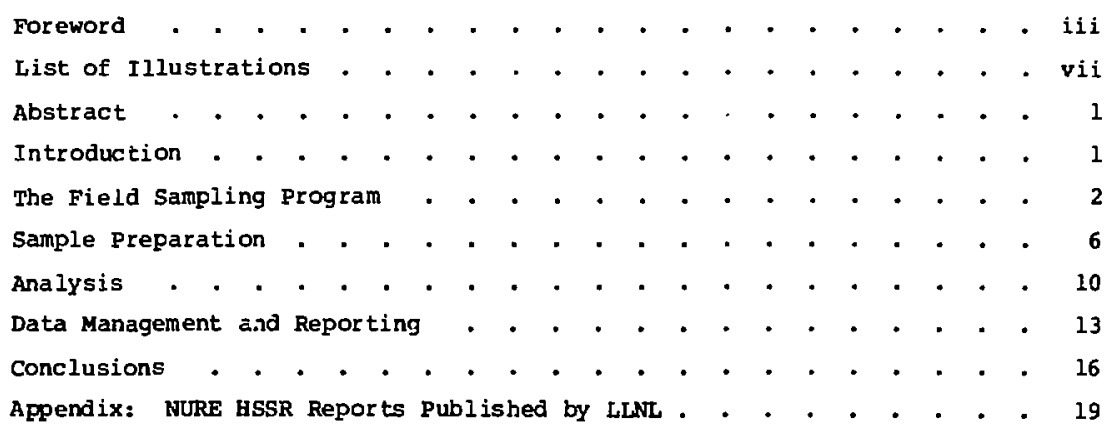


1. Geologic subdivision of the western U.S. used by LLNL to define sampling and reporting areas. . . . . . . . . . . . . 4

2. Just another day in the pursuit of NURE samples. Those with sharp eyes will see help on the way. . . . . . . . . . 5

3. Geopolitical subdivision of the western U.S. designated by the NURE program office for sampling and reporting. . . . . . . 7

4. Status of the ILNL MURE HSSR program at the time of its termination, May 31, 1979. . . . . . . . . . . . . . . B

5. The hard copy file of the LLNL analytical data directories. The files contain between 10 and 20 million words. Also shown is the NURE data sorceress, Cristine Castro. . . . . . 15 
THE NATIONAL URANI UM RESOURCE EVALUATION PROGRAM:

THE HYDROGEOCHEMICAL STREAM SEDIMENT

RECONNAI SSANCE PROGRAM AT LLNL

\begin{abstract}
From early 1975 to mid 1979, Lawrence Livermore National Laboratory (LLNL) participated in the Hydrogeochemical Stream sediment Reconnaissance (HSSR), part of the National Uranium Resource Evaluation (NURE) program sponsored by the Department of Energy (DOE). The Laboratory was initially responsible for collecting, analyzing, and evaluating sediment and water samples from axproximately 200,000 sites in seven western states. Eventually, hewever, the NURE program redefined its sampling priorities, objectives, schedules, and budgets, with the increasingly obvious result that LWNL objectives and methodologies were not compatible with those of the NURE program office, and the LINL geochemical studies were not relevant to the program goal. The LLNL portion of the HSSR program was consequently terminated, and all work was suspended by June 1979. Of the 38,000 sites sampled, 30,000 wers analyzed by instrumental neutron activation analyses (INAA), delayed neutron counting (DNC), optical smission spectroscopy (OES), and automated chloride-sulfate analyses (SC). Data from about 13,000 sites have been formally reported. From each site, analyses were published of about 30 of the 60 elements observed. Uraniun mineralization has been identified at several places which were previously not recognized as potential uranium source areas, and a number of other geochemical anomalies were discovered.
\end{abstract}

\title{
INTRODUCTION
}

Have you always wanted a gold mine? You might try looking near 4293900N 2B6350E, 4285600N - 320050E, or 424450N - 332800E on the Universal Transverse Mercator Grid. Or perhaps you want to study the transport of mercury through sediments into water and thence to fish. You could easily do that in many drainages with sediments containing over 1000 ppon of nercury that empty into Lake Meade. 
These and a host of other results have been obtained as a by-product of the Lawrence Livermore National Laboratory"s (LLNL) work on the Hydrogeochemical Stream Sediment Reconnaissance (HSSR), which is part of the National Urar: um Resource Evaluation (NURE) program. The original purpose of the NURE program was to identify areas favorable for uranium exploration. After preliminary negotiations during 1974 the Laboratory became officially involved in early 1975, and agreed to assume responsibility for evaluation of Washington, Oregon, California, Arizona, Nevada, Utah, and Idaho. At that time the project was designed to extend over 5 years and include about 200,000 sites at which sediment and water samples were to be collected, analyzed, and evaluated; however, after the NURE program staff had redefined sampling priority, objectives, schedules and budgets some nine times, their objective evolved into "Refining Estimates of National Uranium Reserves." It became increasingly obvious that LLNL's objectives and methodologies were inconsistent with those of the Grand Junction NURE program office, and that the LLNI geochemical studies could not be used to improve reserve estimates. As a consequence, the frTNL portion of the ASSR program was terminated, and all work was suspended by June 1979.

of the 38,000 sites sampled, 30,000 were analyzed by instrumental neutron activation analyses (INAA), delayed neutron counting (DNC), optical emission spectroscopy (OES), and automated chloride-sulfate analyses (SC). Data from about 13,000 sites have been $f r$ mally reported. From each site, analyses were published of about 30 of the 60 elements observed. Uranium mineralization has been identified at several places which were previously not recognized as potential uranium source areas, and a number of other geochemical anomalies were discovered.

\section{THE FIELD SAMPLING PROGRAM}

Because there was no DOE reporting plan or sampling rationale at the beginning of the program, each contractor laboratory formulated its own

\footnotetext{
* Lawrence Livermore National Laboratory (LINL), Los Alamos Scientific Laboratory (LASL), Savannah River Laboratory (SRL), and Oak Ridge Gaseous Diffusion Plant (ORGDP).
} 
plan. Under David Leach's direction, LLNL geoscience division personnel divided the western states into geologically similar regions (Fig. 1 ). Several pilot studies within each region would detekmine the geochemical differences between locations known to have uranium occurrences and locations where none were known. Based on the pilot studies, the sampling, analytical, and interpretive procedure was to have been formulated uniquely for each of the geological regions. Pilot projects were completed on the Eastern Sierra, Six-Basin-Humboldt, Southern Nevada I and II, and Northwest Nevada regions. Some of the more interesting and surprising findings were: (1) in arid regions because the finer particles were transported by aeolian processes between drainages, only coarser sediments were chemically representative of the surrounding uplands, (2) playa samples were not valid geochemical jndicators of uranium in the surroundings, (3) field-acidified water samples were trace-element-stable for many months, and (4) groundwater was far more geochemically important and seasonally invariant than surface water (streams, lakes, etc.).

Based on these results, a sampling density of approximately one site per 6 to $B$ square miles was selected for the Basin-Range province. Sites were located on 7-1/2- or 15-minute topographical maps, which were used to prepare specifications of contracts for field sampling. The sites chosen were in drainage paths so that geochemical measures cf the surrounding highlands could be obtained. In larger drainages a site was located at the mouth of each tributary. Contractors were required to obtain about $2-1 / 2 \mathrm{~kg}$ of uncontaminated sediment at or near each of the plotted sites, and a water sample if any were available. Where water was found, conductivity, pH, alkalinity, Eh or dissolved oxygen, and temperature were measured in the field. Water samples were collected through a $0.4-\mu$ pore filter. A one-half liter sample was acidified with nitric acid in a polyethylene bottle. A second unacidified sample was bottled for analyses. The sediment; two water samples; filter; a polaroid picture of the site; and a form showing location, field measurement data, and comments regarding potential contamination were all forwarded to LLNL.

Some of the comments provide interesting stories in themselves. A sequence recorded by one geologist follows: 


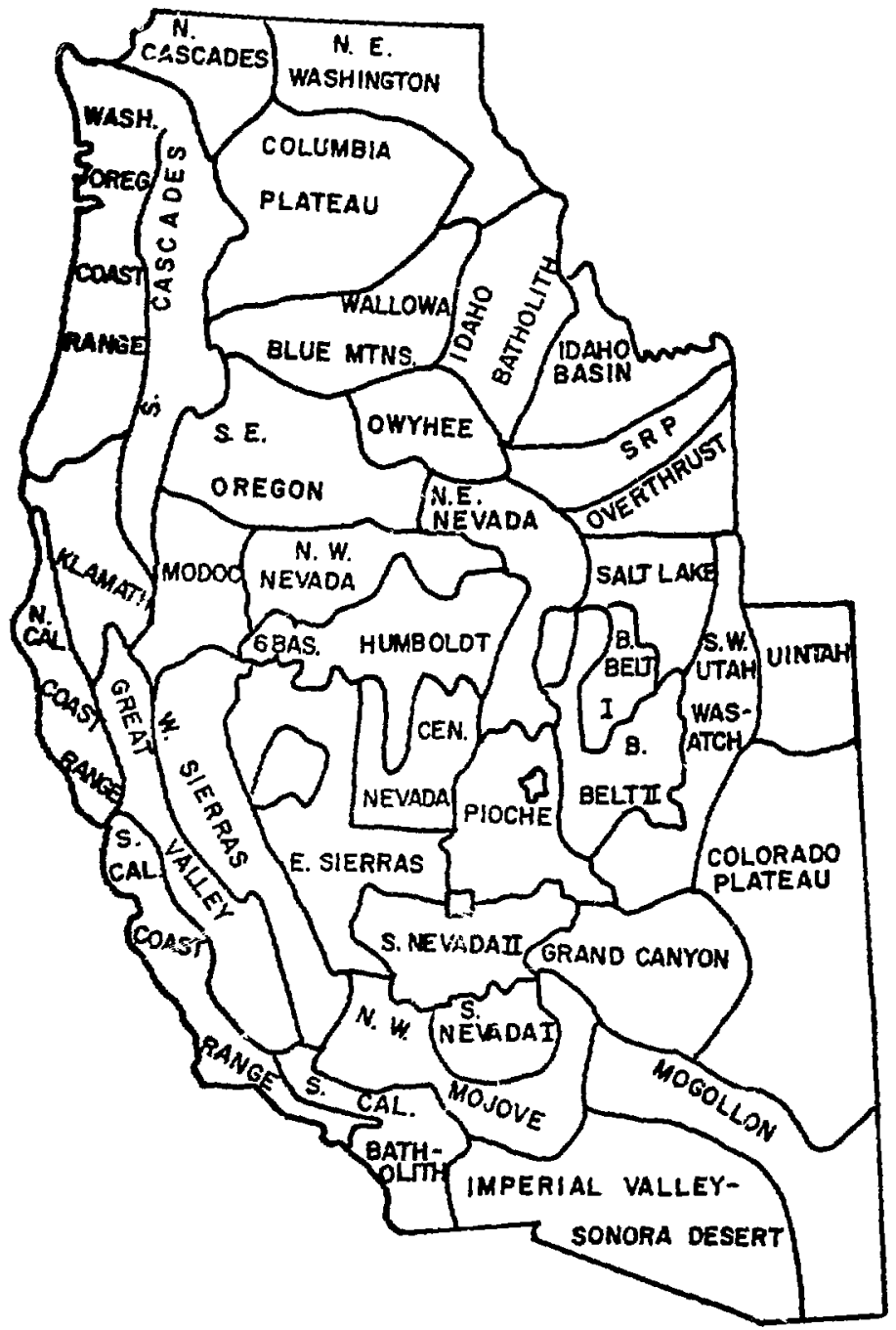

EIG. 1. Geologic subdivision of the western U.S. usec by LLN to define sampling and reporting areas. 
Site No.

5242].

52422

52424

52427

52432
No stream, soil sample

No stream, site on someone's lawn (dumb)

Stream overgrown

High barbwire fence, site moved

Bitten by owner's (expurgated) dog. Now on way to emergency ward in Palmdale. Large hairy dark dog with jaws of great white shark.

The scenario goes on to mention such other unpleasantness as rattlesnakes, $63^{\circ} \mathrm{C}\left(145^{\circ} \mathrm{F}\right)$ temperatures, broken springs and axles, and ruptured fuel tanks. Figure 2 shows another hazard faced when sampling the Far West.

Approximately $5 \%$ of the sites were revisited and resampled by LLNL geologists for quality control and reliability. In almost every case the contractor was within $200 \mathrm{~m}$ of the mapped site, and the samples were not more than $15 \%$ different in trace element composition from the check samples.

The first group of LLNL sampling programs was started in early 1977 . In mid 1977, the Bendix Field Engineering Corporation was retained as site and

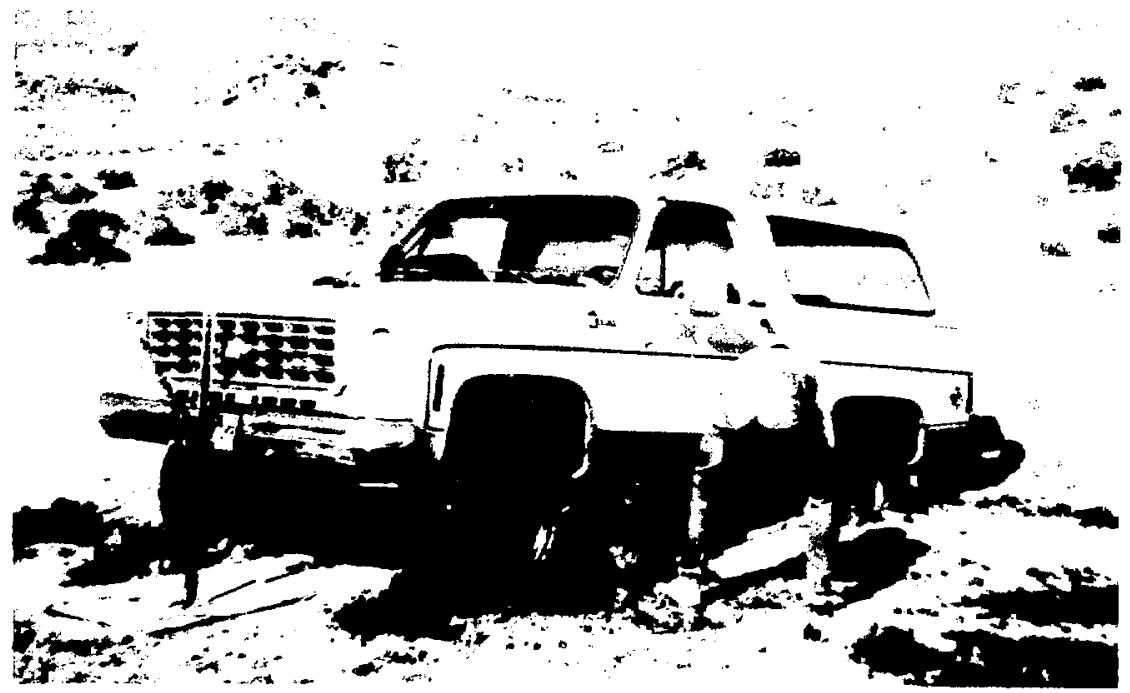

FIG. 2. Just another day in the pursuit of NURE samples. Those with sharp eyes will gee help on the way. 
support contractor by the Grand Junction NURE program office, and to report and interpret results for the HSSR programs. Bendix's specification that sampling and analyses be reported by quadrangle (Fig. 3) caused major difficulties for LLNL because the data already being collected did not completely cover any of the reporting areas and, in general, none of the geologic regions are bounded by quadrangle lines. * We therefore issued a new set of contracts (in early 1978) to "fill in" blank reporting areas, even though the pilot data used to specify sampling technique were not necessarily applicable. Because the NURE program office accelerated the reporting schedule, relevant pilot studies could not be done before we let new regional reconnaissance contracts. In the I Jaho Batholith, Idaho Basins, northeast Washington, the colorado Plateau, and the California Coast Range, new pilot studies were initiated. In all cases, however, results such as particle size studies and leachability were unavailable before final sample collection and processing. In contrast to the arid Basin and Range province, the finest sediments in northeast washington were best associated with regional geochemistry. The samples from that area had to be processed twice because the processor had completed packaging coarse material before it was found that fines were needed. The historical splits of the samples were used to determine the correct size fraction (see Sample Preparation). When the HSSR work at LINL was terminated, some of the "fill in" contracts were incomplete. About 215,000 pounds of material had been collected. The status of sampling, analyses, and reporting is shown in Fig. 4; note the hybrid geologic-political boundaries.

\section{SAMPLE PRE":RATION}

Each sample received at LLNL was inventoried and one copy of the field form was removed. Sediment and acidified water samples were sent to processing contractors with the remaining field forms and labels. The unacidified sample was sent to LINL analytical chemistry for special chemical (SC) analysis. The sediments were oven-dried and split into two fractions. One fraction (l $\mathrm{kg}$ ) was retained as an historical sample, and the other was sieve-sorted. The appropriate size fraction, determined during the pilot studies, was blended:

\footnotetext{
"Additional difficulties were created in the data handling.
} 


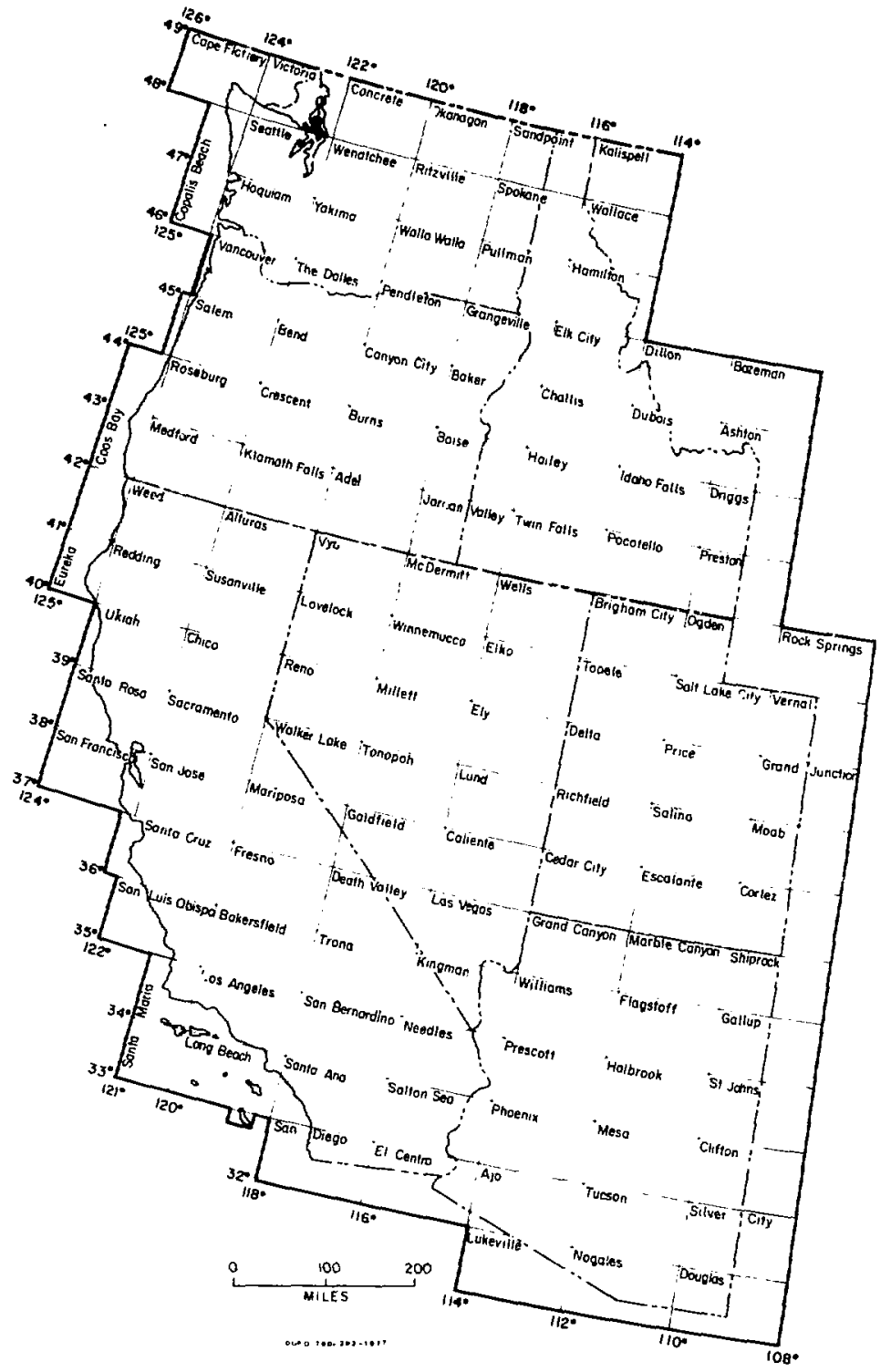

FIG. 3. Geopolitical subdivision of the western U.S. designated by the NURE program office for sampling and reporting. 


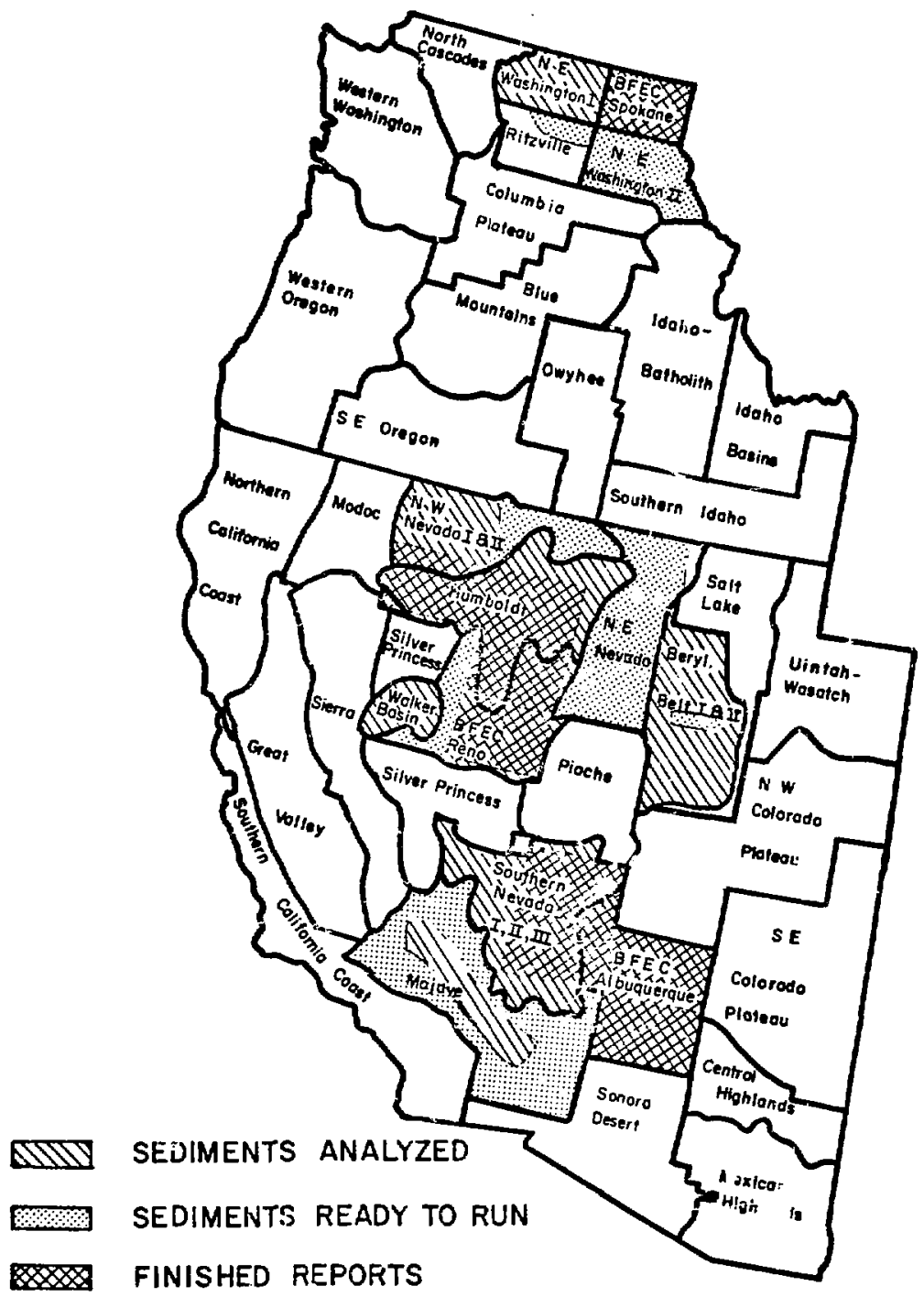

FIG. 4. Status of the LLNL NURF MSSR program at the time of its completion, May 31, 1979. 
$1 \mathrm{~g}$ was packed in a polyethylene "rabbit" for neutron activation analysis, approximately $1 \mathrm{~g}$ was sealed in a vial for OES, and about $200 \mathrm{~g}$ was placed in a polyethylene bottle as an analytical historical sample. The contractor indicated the site number on gummed labels (supplied with the samplss and processing equigment) and placed a label on each split of the sample. A computer card was punched with the site number and weights of samples. Every tenth sediment was sampled in duplicate for analytical quality essurance.

A 20-ml aliquot was removed from each acidified water sample and the remainder was placed in an oven (in a polyethylene-bag-lined polyethylene bottle) until dry. The polyethylene bag was removed, rolled up and placed in a vial, and the vial was placed in a rabbit for DNC uranium analyses. The site number and volume were punched on a card when the aliquot was removed, and the card was forwarded to the data processors. The dried sample was analyzed for uranium and the 20-ml aliquot for 20 elements by OES.

In sumary, each site restited in the following samples, assuming both water and sediment were present:

\section{Sediments}

aistorical - $1 \mathrm{~kg}$ aried but unprocessed

Analytical - $1 \mathrm{~g}$ discarded after analysis

Historical analytical - $200 \mathrm{~g}$ of appropriate size for analysis

Optical emission - $1 \mathrm{~g}$ appropriate size fraction

\section{Water}

Optical emission - $20 \mathrm{ml}$ discarded after analysis Analytical historical - $500 \mathrm{ml}$ dried and stored in rabbit Special chemistry - $200 \mathrm{ml}$ discarded after analysis

At some sites only water was collected (groundwater from a well, for example) and at dry sites only a sediment was collected. During sampling in northern Arizona in the 1977-1978 drought year, an area or 7000 square miles yielded only one surface-water sample. Many of the historical analytical samples are still retained at ILNL * for potential future applications. They would be useful Eor environmencal impact studies, hydrogeochemicrl mobility studies (waste disposal), strategic mineral surveys, geochronology studies, etc.

\footnotetext{
*Also at ORGDP when the HSSR archival storage has been established for dll of the grogram laboratories.
} 
ANALYSIS

The various samples were analyzed for chemical composition by a variety of methods. The sample analyeis system was under the direction of Chuck Smith of the LINL Nuclear Chemistry Division. The elements measured and detection limits under the conditions used are listed in Table 1 . Not all elements were reported.

The automated INAA utilized cast-polyetbylene capsules called "rabbits" as sample containers. The rabbits, each containing 1 to $2 \mathrm{~g}$ of sample, were blown by compressed nitrogen through polyethylene tubing into and out of the reactor, into and out of a delayed neutron counter, to one of four gania say detectors, and finally to storage. The activation analysis was controlled by computers which identified each rabbit and routed it successively into the reactor for a short irradiation--to the delayed neutron counter for uranium determination--to the delay station to allow decay of short-lived isotopes--to one of the ganma detectors coupled to pulse height analyzers--back to the reactor for a longer irradiation-and finally to storage. The computers also wrote the data-rabbit number, reactor Elux, irradiation times, delayed neutron count, and gamma spectrum-on a recorder disk. It took 33 minutes for a rabbit to go through the entire sequence, but a rabbit was entering ajd leaving the system every 2.5 minutes. The computers tracked and controlled an average of 13 rabbits at any one time. After storage for one week the gama spectra of the rabbits were again examined for longer-lived nuclides. The combined first and second gamma spectra comprised the INAA data source. One thousand INAA analyses could routinely be performed in a week. Nearly 70,000 spectra were processed during the program.

The dried water samples were analyzed by irradiating them for a short time ( 30 seconds) and counting the delayed neutron emission to determine uranium. Twenty-four other elements in the water were measured on the RF plasma source optical emission spectrometer (OES).

Except for its high degree of automation, the unique feature of the ILWL neutron activation analyses was the method of spectral data reduction.

Each and every gama ray in the spectrum was identified with an isotope. Then by a series of computer controlled comparisons, the best fit to the observed spectrum was found and reliability was estimated for each isotopic assignment. There were also invariably a few "unidentified" gamma reys which were usually due to statistical fluctuations in the background or isotopes 
TABLE 1. Elements detected, detection limits and sample types for the NURE analytical system.

\begin{tabular}{|c|c|c|c|c|c|c|c|}
\hline Element & $\begin{array}{l}\text { Detection } \\
\text { limit (ppm) }\end{array}$ & $\begin{array}{l}\text { Method } \\
\text { sample }\end{array}$ & $\begin{array}{l}\text { and } \\
\text { type }\end{array}$ & Element & $\begin{array}{l}\text { Detection } \\
\text { limit (ppm) }\end{array}$ & $\begin{array}{l}\text { Method } \\
\text { sample }\end{array}$ & $\begin{array}{l}\text { and } \\
\text { type }\end{array}$ \\
\hline Al & 50 & INAA & $\mathbf{S}$ & $\bar{I}$ & 8 & INAA & $\mathbf{s}$ \\
\hline Al & 0.006 & OES & $W$ & Ir & 100 & INAA & $\mathbf{s}$ \\
\hline Ag & 7 & INAA & $\mathbf{S}$ & $\mathrm{K}$ & 10,000 & INAA & $\mathbf{s}$ \\
\hline As & 3 & INAA & $\mathbf{s}$ & $\mathrm{K}$ & 0.079 & OES & $w$ \\
\hline As & 0.140 & OES & $W$ & La & 0.3 & INAA & $\mathbf{s}$ \\
\hline $\mathrm{Au}$ & 0.01 & INAA & $\mathbf{s}$ & $\mathbf{L i}$ & 0.001 & OES & $\boldsymbol{W}$ \\
\hline $\mathrm{Ba}$ & 200 & INAA & $\mathbf{s}$ & $\mathrm{Lu}$ & 0.1 & INAA & $\mathbf{s}$ \\
\hline B & 0.016 & OES & $\mathbf{w}$ & $\mathrm{Mg}$ & 50 & TNAA & $\mathbf{s}$ \\
\hline $\mathrm{Br}$ & 0.8 & INAA & $\mathbf{S}$ & $\mathrm{Mg}$ & 0.002 & OES & W \\
\hline $\mathrm{Ca}$ & 20,000 & INAA & $\mathbf{s}$ & Mn & 0.2 & INAA & $\mathbf{s}$ \\
\hline $\mathrm{Ca}$ & 0.004 & OES & $w$ & Mn & 0.001 & OES & W \\
\hline $\mathrm{cd}$ & 50 & INAA & $\mathbf{S}$ & Mo & 30 & TNAA & $\mathrm{s}$ \\
\hline $\mathrm{cd}$ & 0.001 & OES & $\boldsymbol{W}$ & Mo & 0.006 & OES & W \\
\hline $\mathrm{Ce}$ & 15 & TNAA & $\mathbf{s}$ & $\mathrm{Na}$ & 20 & INAA & $\mathbf{s}$ \\
\hline $\mathrm{Cl}$ & 200 & INAA & $\mathbf{S}$ & $\mathrm{Na}$ & 0.004 & OES & $\boldsymbol{W}$ \\
\hline $\mathrm{Cl}$ & 2 & sc & $w$ & Nd & 50 & INAA & $\mathbf{s}$ \\
\hline $\mathrm{cc}$ & 2 & INAA & $\mathbf{S}$ & $\mathrm{Ni}$ & 2000 & INAA & $\mathbf{s}$ \\
\hline Co & 0.003 & OES & $W$ & $\mathbf{N i}$ & 0.008 & OES & $\boldsymbol{H}$ \\
\hline $\mathrm{Cr}$ & 10 & INAA & $\mathbf{S}$ & Os & 5000 & INAA & $\mathbf{s}$ \\
\hline cs & 1 & INAA & $\mathbf{s}$ & $\mathbf{p}$ & 0.002 & OES & $\omega$ \\
\hline $\mathrm{Cu}$ & 5000 & INAA & $\mathbf{S}$ & $\mathrm{Pb}$ & 0.032 & OES & $\mathbf{W}$ \\
\hline $\mathrm{Cu}$ & 0.001 & OES & $\boldsymbol{W}$ & $\operatorname{Pr}$ & 1000 & INAA & s. \\
\hline Dy & 0.5 & INAA & $\mathbf{s}$ & Pt & 1000 & INAA & $\mathbf{s}$ \\
\hline Er & 200 & TNAA & $\mathbf{S}$ & $\mathrm{Pu}$ & 0.00003 & DNC & $\mathbf{s}$ \\
\hline Eu & 0.3 & INAA & $\mathbf{S}$ & Pu & 0.0000003 & DNC & $W$ \\
\hline $\mathrm{Fe}$ & 1000 & INAA & $\mathbf{S}$ & $\mathrm{Rb}$ & 50 & INAA & $\mathbf{s}$ \\
\hline $\mathrm{Fe}$ & 0.002 & OES & $\mathrm{W}$ & Re & 10 & INAA & $\mathbf{s}$ \\
\hline $\mathbf{G a}$ & 100 & INAA & $\mathbf{s}$ & $\mathrm{Rh}$ & 100 & INAA & $\mathbf{s}$ \\
\hline Gd & 40 & INAA & s & Ru & 100 & INAA & $\mathbf{s}$ \\
\hline $\mathrm{Ge}$ & 10,000 & INAA & $\mathbf{S}$ & $\mathrm{Sb}$ & 0.5 & INAA & $\mathbf{S}$ \\
\hline Hf & 2 & INAA & s & Sc & 0.03 & INAA & $s$ \\
\hline $\mathrm{Hg}$ & 300 & INAA & $\mathbf{s}$ & Se & 5 & INAA & $s$ \\
\hline
\end{tabular}


TABLE 1. (Continued.)

\begin{tabular}{|c|c|c|c|c|c|c|}
\hline Element & $\begin{array}{l}\text { Detection } \\
\text { limit (ppm) }\end{array}$ & $\begin{array}{l}\text { Nethod and } \\
\text { sample type }\end{array}$ & Element & $\begin{array}{l}\text { Detection } \\
\text { limit (ppm) }\end{array}$ & $\begin{array}{l}\text { Method } \\
\text { sample }\end{array}$ & $\begin{array}{l}\text { and } \\
\text { type }\end{array}$ \\
\hline $\mathbf{S i}$ & 100,000 & INAA $\mathbf{S}$ & U & 0.8 & INAA & $\mathbf{s}$ \\
\hline $\mathbf{S i}$ & 0.005 & OES $W$ & U & 0.01 & DNC & $\mathbf{s}$ \\
\hline $\mathrm{Sm}$ & 0.3 & INAA $\mathrm{S}$ & $\mathbf{U}$ & 0.0001 & DAC & $\boldsymbol{H}$ \\
\hline Sn & 200 & INAA $S$ & U & 0.036 & OES & $W$ \\
\hline $\mathrm{So}_{4}=$ & 5 & SC $w$ & v & 10 & INAA & $\mathbf{s}$ \\
\hline Sr & 350 & INAA $S$ & $v$ & 0.002 & OES & $W$ \\
\hline Sr & 0.007 & OES $\mathrm{W}$ & $\mathbf{w}$ & 10 & INAA & $s$ \\
\hline $\mathrm{Ta}$ & 2 & INAA $S$ & $\mathrm{Yb}$ & 0.8 & INAA & $\mathbf{s}$ \\
\hline $\mathrm{Tb}$ & 0.5 & INAA $s$ & $\mathrm{Zn}$ & 100 & INAA & $s$ \\
\hline Th & 2 & INAA $\mathbf{S}$ & $\mathrm{Zn}$ & 0.004 & OES & พ \\
\hline $\mathbf{T} \mathbf{i}$ & 1000 & INAA $\mathbf{S}$ & $\mathbf{z r}$ & 2000 & INAA & $\mathbf{s}$ \\
\hline $\mathbf{T i}$ & 0.001 & OES $W$ & $\mathbf{z r}$ & 0.002 & OES & $\mathbf{w}$ \\
\hline
\end{tabular}

Note: INAA-instrumental neutron activation analyses OES-plasma source optical emission spectrometer

sc-special chemistry anion optical absorption analysis

DNC-delayed neutron counting

s-sediment sample

W-water sample

present below their detection limits. This computer program has identifiers for isotopes of about sixty elements and its output is the number of atoms at the end of irradiation. A second computer program converted the isotope atoms to elemental fractions of the sample using the sample weights, reactor flux, isotopic cross sections and abundances, and other factors. This second program also accepts the delayed neutron count data and subtracts fission product production where that is important (molybdenum). In case there were two or more isotopes produced from a single element, results were weighted and averaged, and a single concentration number and error was estimated. Resultant data were the neutron activation analysis input to one of the data directory files. The sample numbers, and not the site numbers or coordinates, are the only identifiers in the INAA analytical data base directory. 
The induction-controlled plasma-source optical emission spectrograph was used to analyze the dissolved cations in acidified water or acid leaches of sediment samples. Aliquots of each sample were placed in an automatic computer-controlled sample changer which sequentially read an identifying computer card, transferred a premeasured amount of unknown to the plasma torch, rinsed the sample tube, and recorded the spectral output for twenty-four ejements. This procedure was repeated three times for each sample and the averaged results were recorded on a floppy disk. A standard solution was run after each sixth sample to measure long-term instrumental drift. The data were entered from the disk into a preprocessing computer where the sample composition was derived, considering such factors as the aliquot ratio and instrumental drift. The results were then transferred to tape and stored in another of the data directory files. Throughput of the system averaged about 150 samples per day over an ll-month period.

The special chemistry, chloride, and sulfate analyses were performed with an instrument called a Technicon AutoAnalyzer (TM) on unacidified water samples. This instrument automatically adds chemicais to aliquots of samples and determines the anions by photo absorption analysis. These data are computer-processed and recorded on punched cards as concentratiors of the ions. The cards are read into still another data directory file by sample number.

In addition to these routine analyses, certain samples were examined by special procedures designed to find the trace-element distribution as a function of particle size, association of trace elements with volatile organic compounds, such as humic acid, and the trace-element distribution in the leachable and nonleachable sediments. These special procedures were generally, though not always, associated with pilot or special studies.

\section{DATA MANAGEMENT AND REPORTING}

The reader should now recognize the complexity and bulk of information collected in conjunction with each NURE site. The information stored, collated, and produced came from the field site-visit forms; site latitudelongitude digitizers; sample processors; and INAA, DNC, OES, and SC analyses. The data management system grew under the direction of a number of different people over a period of time and in response to requirement changes. 
The information obtained during sampling was entered by tne sample-collection teams in punched-card-image form on a single sheet called the site-visit form. This form has images of fifty-four IBM-type 80-column cards. Each card carries the site number. The first four cards describe the project, sample collector, map name, date, location (township, range, section, and quarter section), time, and landowner's name and address (assuming landowner wanted a copy of the data). The next three cards describe the site geology, and the remaining forty-seven cards describe the samples collected, sample treatment, field measurement results (alkalinity, pH, temperature), environmental and cultural features, and such features as weather and vegetation. An average of about twenty-five cards was written for each of the 38,000 sites, so the field data set contains about 7,600,000 items. All our data and data management were keyed on the information obtained from these forms. The forms did not have the AMS quadrangle name, since there was no program requirement when they were developed that data be reported by AMS quadrangle. Each geological province was subdivided into subunits called "projects" and it was the original program plan to report results on a project basis. The project name included in the field data file would have been sufficient to identify sites and produce the desired reports. When the requirement for reports in AMS quad form was added, it became necessary to add a data directory file compiled by digitizing each project site's latitude and longitude. ine site digitization adds over 100,000 additional items of data.

The final data file originated from the "field comment" portion of the site-visit form. Each form was keypunched by hand and this data file was keyed on project and site number. Approximately 10,000 field forms contained written comments.

These three data sources were entered into the master control program (HCP) data management system.

The analytical data from INAA, DNC, OES, and SC went into a set of directory files. Each kind of data and each major operation had its own file. The data remained in one or another of these files until an output report was requested. Then, site numbers identified with the desired report area were extracted from MCP using the latitude-longitude boundaries of the area as the sorting criterion. A blank file of the expected data (sample type and analysis) was created and named for each of the site numbers and locations. This file was then used to search all the directory files for the 
expected entries according to either site number or sample number. If an expected entry was missing the site was listed on a "minus" file for that data set. These missing data, if more then a few percent of the total expected, were then found or redetermined through additional analyses. When satisfactorily complete, the relevant data from each of the directories was trassferred into the blanks in the MCP report file. The fact that there is essentially no analytical data in the MASTER control system was a source of ongoing misunderstanding between LLNL and the NURE progiam office (NPO). The LLNL "data base" may be unique in that it contains no data--except that which has been published. It does contain information not required in NURE uniform reports, but of great geochemical significance. For example, it contains precipitation and stream flow conditions at the time of sample collection, as we 1 as the site description and comments.

Finally, the filled report file was used as the generator for data tables, site overlay maps, statistical distribution studies, and graphs.

Figure 5 shows the hard copy files of most of the analytical directory data for those sites $(30,000)$ which were analyzed and may give some idea of

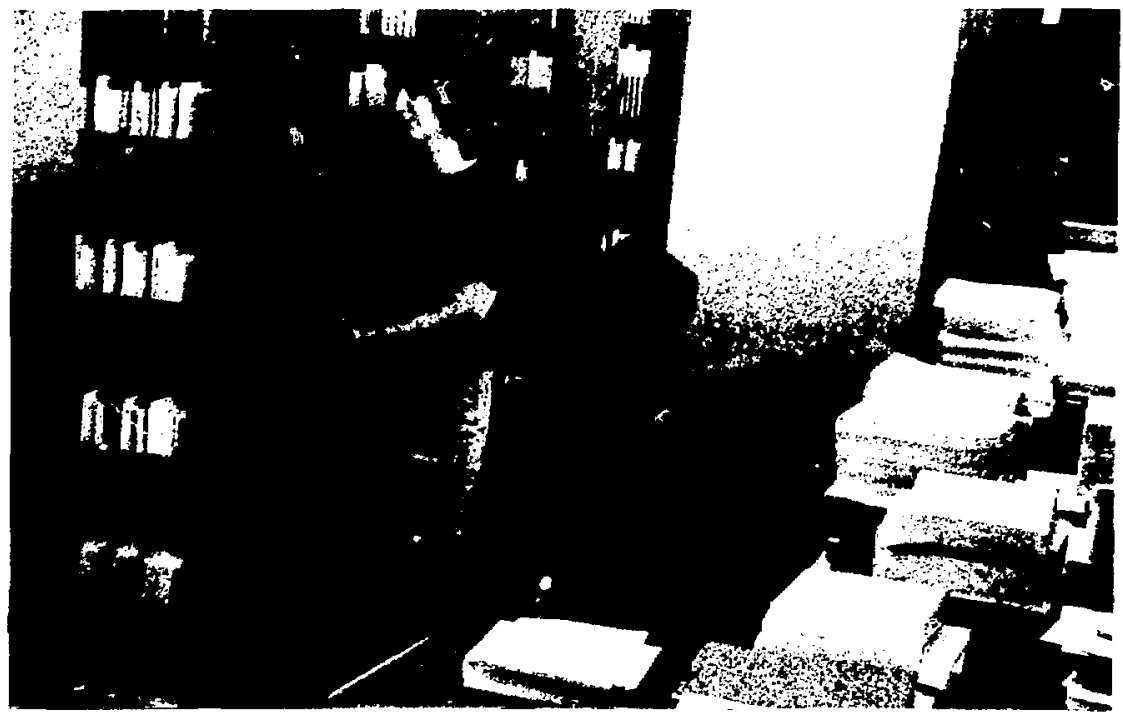

FIG. 5. The hard copy file of the LLNL analytical data directories. The files contain between 10 and 20 million words. Also shown is the NURE data sorceress, Cristine Castro. 
how much paper it takes to write 10 or 20 million computer words. The Appendix contains a listing of the pilot studies and quadrangle reports prepared during the 4-1/2 years LLNL participated in the NURE-HSSR program.

\section{CONCLUSIONS}

The HSSR effort at LWL has been conducted as a sophisticated geochemical reconnaissance of some of the geologically similar subregions of the Western United states. It has been successful to the degree that several new potential uranium districts were suggested. Several areas also showed unusual pcurrences of other strategic elements. It has shown several new constraints on geochemical prospecting, especially as applied to semidesert regions. It has also shown that some relationships and constraints learned from studies of more temperate humid regions do not apply or are misleading in arid areas. It has been unsuccessful in that it conformed to only 76 percent of the requirements finally established by DOE (their number) and, by both DOE and LWNL judgment, has almost nothing to do with uranium reserve estimates and the latest goal of the NURE program.

It would be a disservice to the reader if I did not close with a brief discussion of "what went wrong" with NURE. The complete answer is very complex, but I believe there are some obvious problems. Paramount is uncertain and late program definition by NPO. I beileve this resulted from the origin of the U.S. NURE program. In both Canada and Australia, geochemical exploration had been used to discover significant new uranium resources. The NURE program was patterned after the Canadian survey, without research to determine if the Canadian method worked in the U.S.--it was an early and disconcerting discovery that it did not work in many areas. As NURE goals were changed, the rate of change was faster than the rate of execution, so nothing got done on any but obsolete goals.

As a result of pilot study work at LLNL and broad-based industry and professional-society pressure, the methodology we had originally proposed was incorporated into the stream sediment survey. These methods were more costly than those of the Canadian Survey because of the more complex geologichydrologic situation in much of the U.S. The available money was assigned to "priority" regions on the assumption that later funding would be obtained for areas with less priority. The catch was that no agreement could be reached on 
just which regions had high, medium, or low priority. As soon as a region was assigned "low" priority, something would happen (such as discovery of uranium) and all the priorities would be redetermined.

Another cause of difficulty was failure to reach early agreement with the NPO on the role of the Laboratory in the execution of the Hydrogeochemical stream sediment survey. The initial LNL proposal was to collate and interpret the data by means of sophisticated statistical methods such as pattern recognition. The NPO wanted us to use our sampling and analytical capabilities to generate the data without interpretation. We agreed to expand our activities to include data gathering as well as interpretation, but the NPO never really agreed that we would be permitted funds for interpretation.

However, in spite of these difficulties and misunderstandings, the overall outcome was positive. A great deal new was learned about geochemical prospecting in semiarid regions. This knowledge, the methodologies developed from our early pilot studies, and the statistical approaches developed by Stanley Grotch and others have been widely adopted. U.S. firms and others working in foreign semiarid regions, such as Australia, have patterned their efforts after these pioneering res ...

In the final analysis, the va... if the LuNL effort will be its impact on finding strategic resources, and $i$ ts impact on and acceptance by the geosciences community. We at LLNL regret that som: of the broader aspects of this extensive and systematic survey have been forever lost. In addition, the NURE-HSSR program at LLNL was not only successful in identifying uranium, but yielded information which can open a new epoch in geosciences. 
18 
Development and vtilization of a Large Geochemical Data Base for Uranium Resource Assessment, S. L. Grotch, B. S. Gumm, 1 p., UCRL-81694, Abstract (No date) .

Stream-Sediment Orientation Study for Uranium in the Artillery Peak Quadrangle, Mohave County, Arizona, D. L. Leach, R. P. Puchlik, S. A. Schultz, 2 p., DCRL-82465, Abstract (No date).

Distribution of Uranium in Sediment Samples as Determined by Multi-Element Analysis, J. D. Tewhey, 5 p., UCRI-79274, Sumary (No date).

Hyörogeochemical and stream Sediment Survey (NURE). Part I, Preliminary Report on the Walker River Basin Study (California, Nevada), 106 p., UCID-16911, Part-1 (7/1/76).

Hydrogeochemical and stream Sediment Survey (NuRE). Part 2, Preliminary Report on the Winnemucca Dry Lake Basin Pilot Study (Novada), UCID-16911, Part-2 GJBX-41(76) (8/1/76).

Bydrogeochemical and stream Sediment Survey (NURE). Part 3, Preliminary Report on the Smoke Creek Desert Basin Pilot Study (Nevada), UCID-16911, Part-3 GJBX-42(76) $(8 / 1 / 76)$.

Fydrogeochenical and Stream Sediment Survey (NURE). Part 4, Preliminary Report on Cave Valley Basin Pilot Study (Nevada), ucID-16911, Part-4 GJBX-43(76) (8/1/76).

Fydrogeochemical and Stream Sediment Survey (NURE). Part 5, Preliminary Report on the Roach Lake Basin Pilot Study (Nevada), UCID-16911, Part-5 GJBX-43(76) $(8 / 1 / 76)$.

Hydrogeochemical and Stream Sediment Reconnaissance Program at ILL, J. F. Tinney, 16 p., UCRL-79243 (3/77). 
Hydrogeochemistry of Uranium in the Walker River Basin, California and Nevada, L. V. Benson, D. L. Leach, 5 p., UCRL-79282, Abstract (3/77) .

Description of Quality Assurance in the ASSR Program and Summary of Anal :ical Methods Used, T. L. Steinborn, 2 p., UCRL-79242, Sumnary (3/77).

Geochemical Reconna issance for Uranium in the Arid Reginns of the Western United States, D. L. Leach, 1 p., UCRL-79241, Abstract (3/77).

Energy and Technology Review: Progiess Report, R. B. Crawford, R. L. Cummings, J. R. Prono, R. W. Selden, J. T. Staehle, 30 p., UCRL-52000-77-5 (5/77).

Instrumental Neutron Activation Analyses for the NURE Hydrogeochemical Reconnaissance Survey, C. F. Smith, 4 p., UCRL-79709, Sumary $(6 / 30 / 77)$.

NURE Rabbit and Card Reader, S. C. Bourret, 3 p., UCID-17571 (8/31/77).

Hydrogeochemistry of Uranium in the Walker River Basin, California and Nevada, L. V. Benson, D. L. Leach, 38 p., UCRL-79282 $(10 / 8 / 77)$.

Lawrence Livermore Laboratory Hydrogeochemical and Stream Sediment Reconnaissance, Raw Data Report Cave Valley Orientation Study, Nevada, National Resources Evaluation, B. E. Holder, R. P. Puchlik, C. F. Smith, UCID-17648 $(10 / 77)$.

Lawrence Livermore Laboratory Hydrogeochemical and Stream Sediment Reconnaissance, Raw Data Report Roach Lake Basin Orientation Study, Nevada, National Resources Evaluation, B. E. Holder, K. P. Puchlik, C. F. Smith, UCID-1768I (12/77).

NURAB, a System for Processing Neutron Activated Samples, G. G. McMillan, R. D. Carver, 14 p., UCRL-80259 (4/20/7B).

Hydrogeochemical and Stream Sediment Reconnaissance Basic Data Report for Winnemucca NTwS Quadrangle, Nevada, R. P. Puchlik, UCRL-52469 (5/78). 
Hydrogeochemical and Stream Sediment Reconnaissance Basic Data Report for Kingman NTMS Quadrangle, Arizona, California, and Nevada, B. J. Qualheim, 43 p., UCRL-52549 (7/78) .

Hydrogeochemical and Stream Sediment Reconnaissance Basic Data Report for Las Vegas NIMS Quadrangle, Arizona, California, and Nevada, B. J. Qualheim, 41 p.. UCRL-52550 (7/78).

Artillery Peak Orientation Study, Mohave County, Arizona, R. P. Puch]ik, D. L. Leach, D. Cages, UCRL-52675 (3/12/79) *

Hydrogeochemical and Stream Sediment Reconnaissance Basic Data Report for Millet NTME Quadrangle, wevada, J. L. Wagoner, December 1976, 44 P., 7 illus., 4 fiche; UCRL-52641; PR No. $79-40(4 / 24 / 79)$.

Rydrogeochemical and Stream Sediment Reconnaissance Report for the Deep Creek Mountains, Nevada and Utah, B. Qualheim, UCRL-52686 (4/79).

Artillery Peak Orientation Study, Mohave County, Arizona, R. P. Puchlik et al., March 1979, 28 p., 3 illus., 1 fiche; LLL No. UCRL-52675; PR No. 79-63 (5/21/79).

Hydrogeochemical and Stream Sediment Reconsaissance Basic Data Report for Sanapoint NTMS Quadrangle, Washington, Idaho, and Montana, F. J. Ciminesi, February 1979, 122 p., 6 illus., B fiche; UCRL-52661 (5/31/79).

Hydrogeochemical and Stream Sediment Reconnaissance Basic Data Report for Williams NMS Quadrangle, Arizona, J. L. Wagoner, Pebruary 1979, 77 p., 6 illus., 5 fiche; UCRL-52671 (5/31/79).

Hydrogeochemical and stream Sediment Reconnaissance Repor: for the Tonopah NMs Quadrangle, Nevada, B. Qualheim, March 1979, 58 p., 6 illus., 3 fiche; UCRL-52676; PR No. 79-75 (6/27/79) .

Hydrogeochemical and Stream Sediment Reconnaissance Report for the Lovelock NTMS Quadrangle, Nevada, B. Qualhe im, March 1979, 58 p., 6 illus., 3 fiche; UCRL-52677; PR No. 79-75 (6/27/79). 
Papago Indian Reservation Water Sample Analyses, G. H. Higgins, May 1979, 21 p.; UCID-18187; PR No. 79-89 (7/26/79).

Hydrogeochemical and Strean Sediment Reconnaissance Basic Data Report for the Prescott NTMS Quadrangle, Arizona, R. J. Clark, May 1979, 96 p., 6 illus., 7 fiche; DCRL-52696; PR No. 79-106 (8/31/79). 